\title{
An Algorithmic Approach to the Congenital Vertical Talus
}

\author{
Maryse Bouchard, MD, MSc ${ }^{1,2}$ \\ ${ }^{1}$ Division of Orthopaedics, The Hospital for Sick Children, Toronto, ON; ${ }^{2}$ Department of Surgery, University of Toronto, \\ Toronto, ON \\ Correspondence to: Maryse Bouchard, MD, MSc, 555 University Ave, s107 Toronto, ON, M5G1X8, Canada, E-mail: Maryse. \\ bouchard@sickkids.ca
}

Received: January 3, 2022; Accepted: January 3, 2022; Published: February 1, 2022

DOI: 10.55275/JPOSNA-2022-0002

\begin{abstract}
:
There is scant literature on the best approach to management of the congenital vertical talus with no new techniques described since the serial casting and minimally invasive surgical approach published by Dobbs et al. in 2006. There remain many questions such as what is the optimal surgical technique, what are the lower and upper age limits of various surgical procedures, what to do if casting or the minimally invasive technique do not reduce the talonavicular joint, and what are the optimal postoperative casting and bracing protocols? This manuscript summarizes an algorithmic approach to managing the CVT from casting to postoperative bracing. A stepwise algorithm is described that can be applied to a patient of any age with untreated, neglected, or recurrent deformity. Casting should always be attempted prior to surgery, and surgery should be performed with a deliberate à la carte approach to minimize complications.
\end{abstract}

\section{Key Concepts:}

- Always initiate treatment with serial casting.

- The minimally invasive surgical approach is often sufficient.

- For severely stiff and recurrent feet, consider more extensive soft tissue releases and possible naviculectomy with an à la carte approach to avoid overcorrection, osteonecrosis, and wound healing problems. 


\section{Introduction}

A congenital vertical talus (CVT) deformity is a dorsolateral dislocation of the talonavicular joint. There is severe and rigid plantar flexion of the talus, hindfoot equinovalgus, eversion of the subtalar joint, and fixed dorsiflexion of the midfoot on the hindfoot. ${ }^{1,2}$ It is sometimes described as a rockerbottom foot (Figure 1). CVT occurs in 1 in 10,000 live births, and in approximately half of cases it is associated with neuromuscular or genetic disorders, such as myelomeningocele, sacral agenesis, and arthrogryposis. ${ }^{3-9}$ There is no sex predominance and 50\% percent of children have bilateral deformities. ${ }^{3}$ In isolated deformities, the etiology remains unclear with genetic mutations likely to play a role. , $^{4,10-13}$

Diagnosis of CVT should be confirmed radiographically with anteroposterior (AP) and lateral foot radiographs in neutral or dorsiflexion and a lateral in maximum plantarflexion. ${ }^{12}$ Since the tarsal bones are not yet ossified in the infant, the reduction of the talonavicular

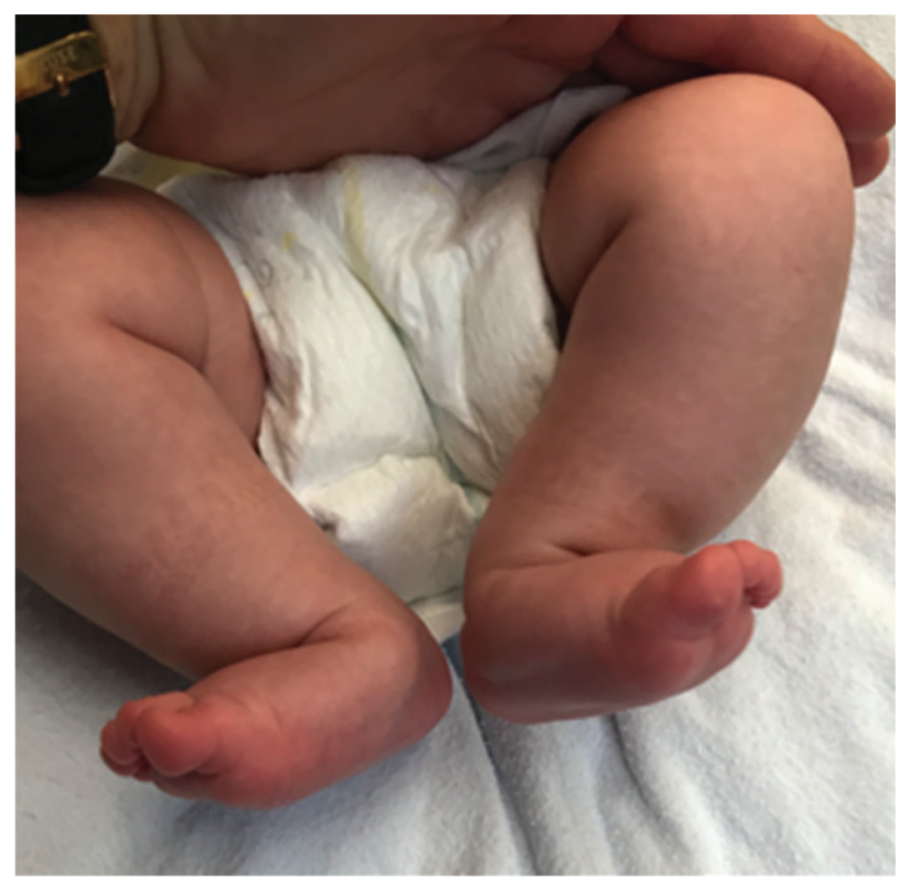

Figure 1. Clinical photograph with medial view of bilateral congenital vertical talus in a newborn demonstrating the rocker-bottom deformity. joint can be assessed using the talar axis-first metatarsal base angle as surrogate landmarks ${ }^{14}$ (Figure 2). These axes should be collinear on the AP and lateral radiograph in the normal foot. In a CVT, the neutral or dorsiflexion lateral view shows vertical position of the talus and plantar flexion of the calcaneus caused by contracture of the Achilles tendon and posterolateral joint capsules. The maximum plantar flexion view shows persistent dorsal translation of the forefoot on the hindfoot caused by fixed dislocation of the navicular. The position of the cuboid in relation to the calcaneus should also be noted, as it may also be dorsally subluxated.

Historically, a congenital vertical talus was treated with extensive surgical release. A reliably effective casting method for the correction of the congenital vertical talus was not demonstrated until 2006. ${ }^{15}$ Dobbs et al. reported the first study showing short-term maintenance of good correction in 19 idiopathic congenital vertical talus deformities treated with a reverse-type Ponseti casting followed by minimally invasive surgery of percutaneous Achilles tenotomy and limited open talonavicular joint (TNJ) capsulotomy with pinning. ${ }^{15}$ Other surgical

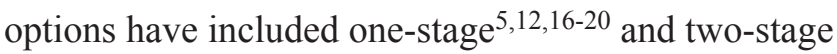
dorsolateral and posterolateral soft tissue releases, ${ }^{3,21,22}$ talectomy, ${ }^{1,23}$ naviculectomy with and without adjacent removal of the medial cuneiform, ${ }^{23-25}$ subtalar arthrodesis, and triple arthrodesis. ${ }^{26-28}$

Currently, surgeons generally perform the minimally invasive Dobbs Technique. ${ }^{15}$ Good clinical and radiographic short-term results of this technique have been reported by Chalayon et al. and Aslani et al., though the recurrence rate was $20 \%$ in the former study. ${ }^{29,30}$ Wright et al. in 2014 reviewed the Dobbs technique in 13 patients (21 feet) with idiopathic and nonidiopathic vertical tali. ${ }^{31}$ They found higher recurrence rates $(33 \%)$ in the nonidiopathic group and if capsulotomy of the TN joint (TNJ) was not performed. ${ }^{31}$ Longer-term outcomes reported by Yang and Dobbs with a mean follow-up of 7 years (range 5 to 11.3 years), showed the patients treated 

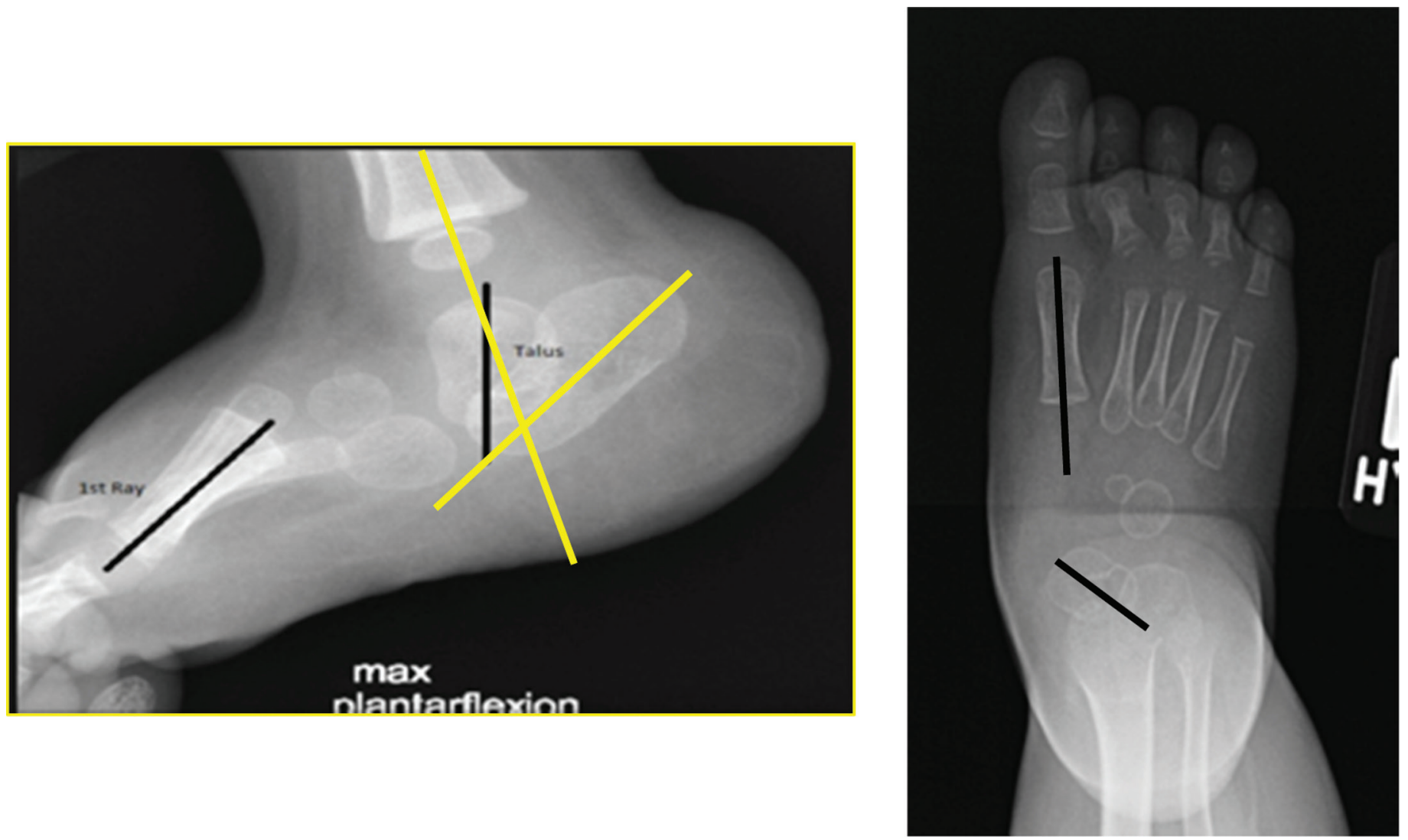

Figure 2. AP and forced plantarflexion lateral radiographs of a foot with congenital vertical talus. The black lines represent the talar and $1^{\text {st }}$ metatarsal axes. On the lateral, the $1^{{ }^{s t}}$ metatarsal is dorsal to the talar axis. On the AP, the apex of the axes is medial. The yellow lines represent the calcaneal and tibial axes. The calcaneus is elevated in the fat pat and plantarflexed representing equinus.

with minimally invasive surgery had improved ankle range of motion, better hindfoot valgus alignment, and superior outcomes scores than those having extensive soft-tissue releases. ${ }^{32}$

Despite the prevalence of CVT, there is scant literature on the best approach to management. No other innovations in surgical approach have been described since the publication of Dobbs' technique in 2006. ${ }^{15}$ There remain many questions as to the optimal patient for a minimally invasive approach, what are the lower and upper age limits, what to do if casting or the minimally invasive technique do not reduce the TNJ, and what the optimal postoperative casting and bracing protocols should be. This manuscript summarizes an algorithmic approach to managing the CVT from casting to postoperative bracing.

\section{Author's Preferred Approach Serial Manipulation and Casting}

Regardless of the age of the patient, isolated or nonidiopathic CVT, or if it is a primary or revision case, always start treatment with serial casting. The younger the patient, typically the more flexible the deformity, therefore starting casting in infancy may yield better results. If correction is progressing well, particularly in older ambulatory children and those who travel long distances for care, below knee casts and bi-weekly casting may be considered. In most patients, at least five casts are required.

Manipulation of the CVT adopts the principles of "reverse-Ponseti" per Dobbs, plantar-flexing and inverting the mid and forefoot with counter pressure applied at the plantarmedial head of the talus. ${ }^{15}$ Similar 
Table 1. Summary Algorithm for Management of Congenital Vertical Talus

Always start with serial casting

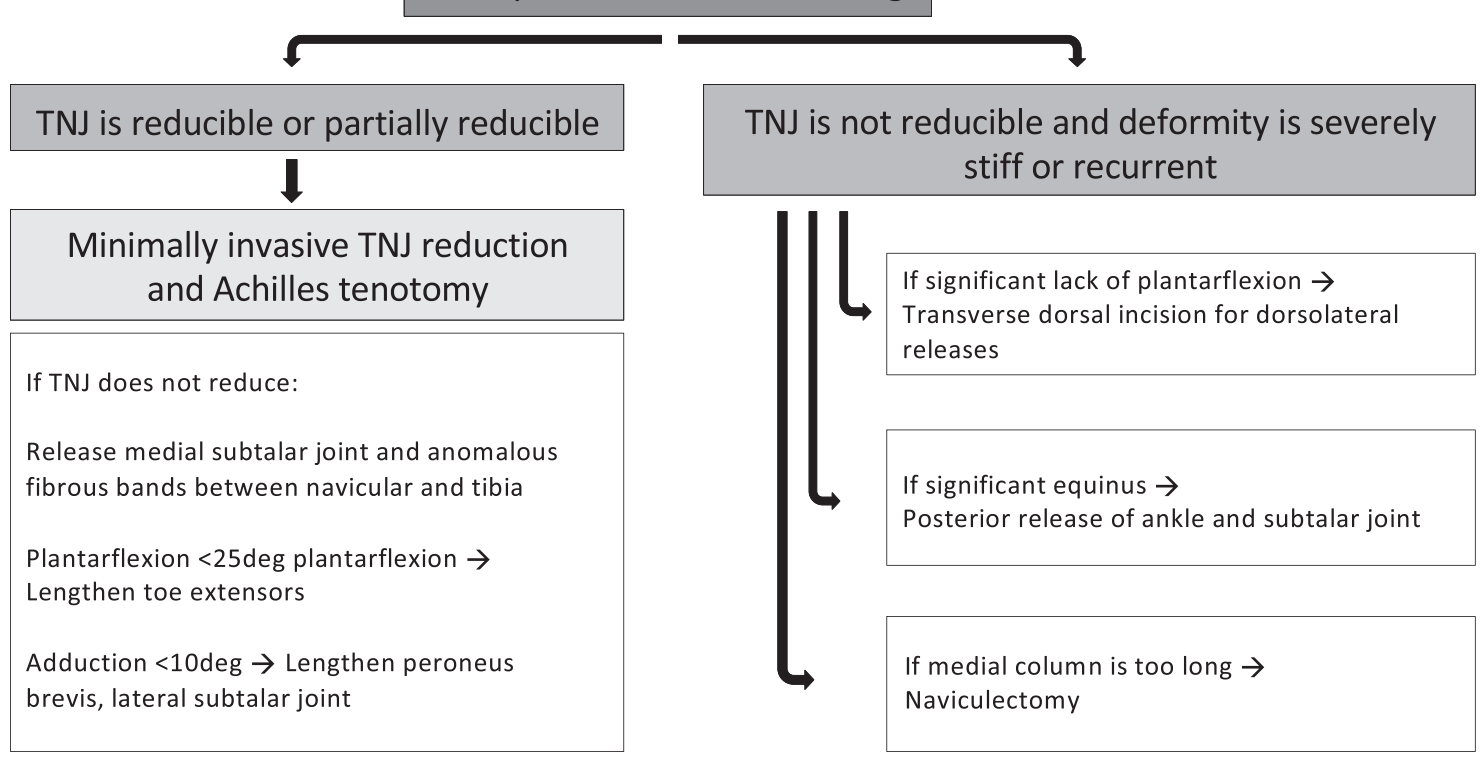
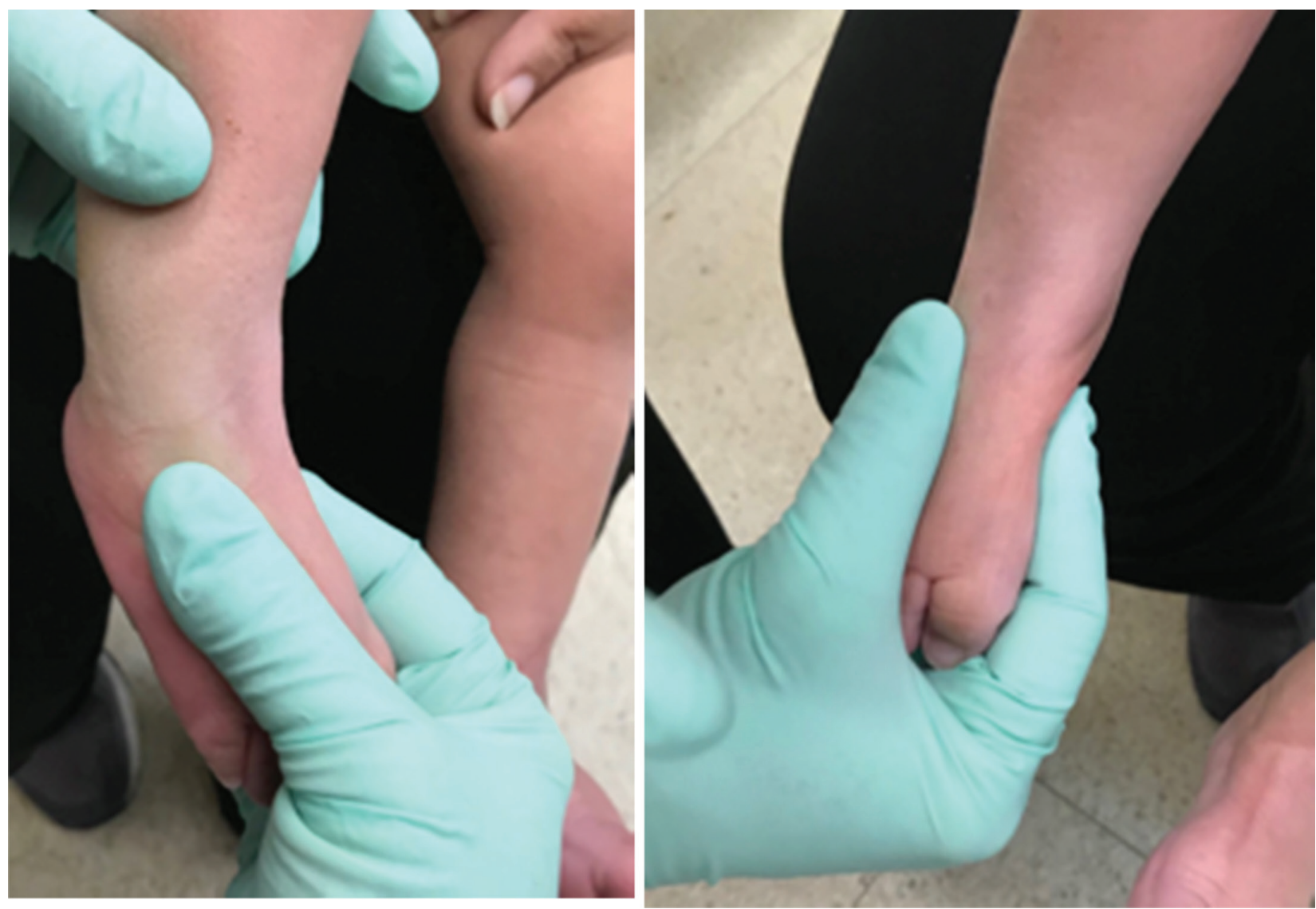

Figure 3. Clinical photographs demonstrating the initial manipulation to stretch the dorsolateral soft tissues. The thumb is applying gentle traction over the sinus tarsi, and the index finger provides a fulcrum plantarmedial at the talar head. 

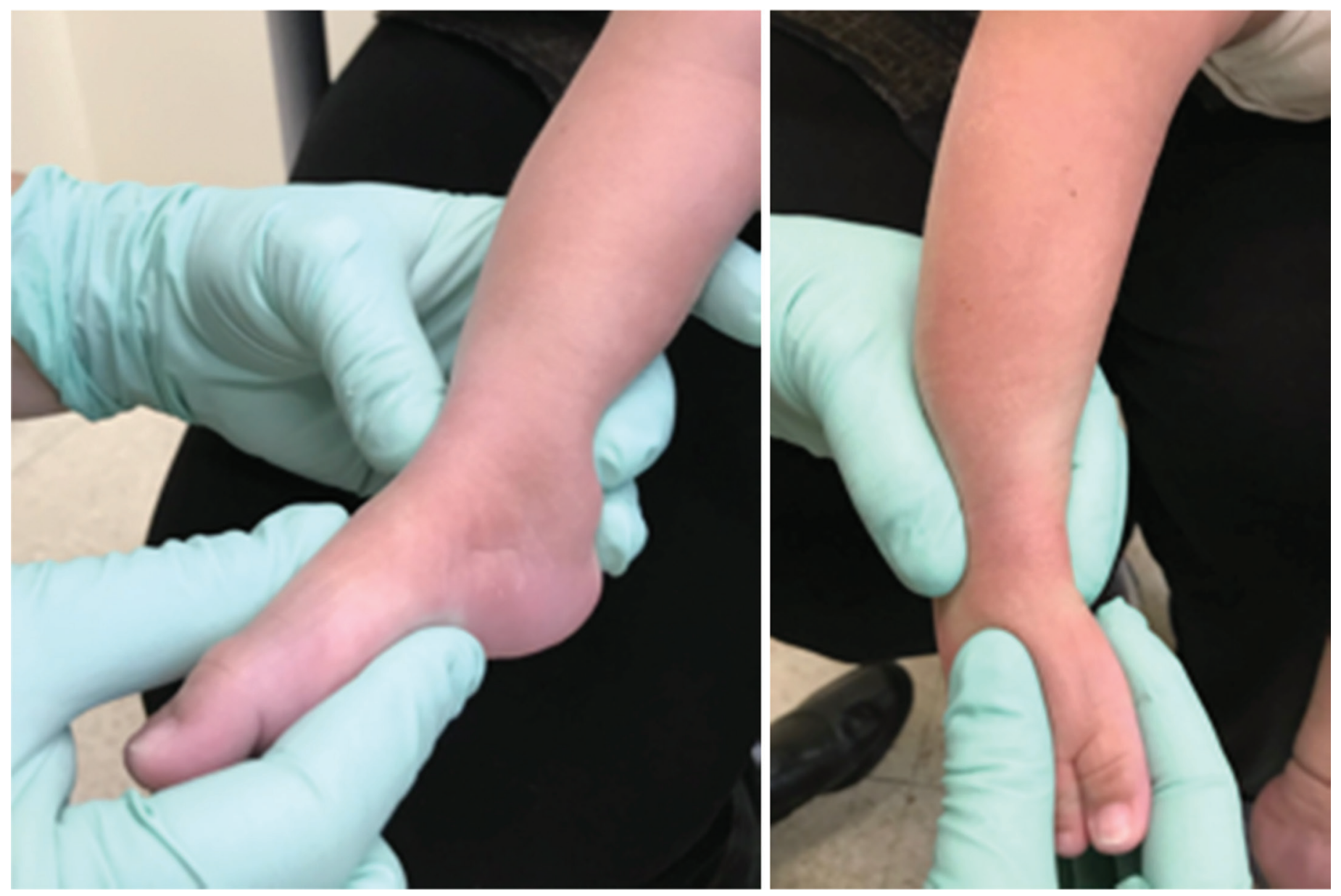

Figure 4. Clinical photographs demonstrating reduction through the midfoot with an adduction moment. The left thumb is stabilizing at the sinus tarsi. The right thumb is on the dorsal navicular and index plantar to the navicular as traction is applied in a distal, adduction and supination moment to mobilize the navicular toward the talar head.

to the C-A-V-E principle for clubfoot casting, there are sequential steps in the manipulation and casting. ${ }^{33}$ First, the lateral structures (peronei, lateral ankle ligaments) are stretched eventually allowing subtalar inversion (Figure 3). Next, the midfoot is reduced bringing the calcaneocuboid joint and TNJ down and medial with gentle traction. Adduction of the midfoot on the hindfoot is then applied (Figure 4). Lastly, and only once inverted subtalar joint alignment is achieved, a plantarflexion moment can be applied at the TNJ to stretch the tibialis anterior and TNJ dorsal capsule. When there is medial TNJ congruency, plantarflexion through the ankle can be performed to stretch the anomalous fibrous tissues between the navicular and anterior distal tibia. Always ensure the cast is molded at the medial arch to maintain TNJ reduction (Figure 5). Radiographs are obtained to confirm the TNJ is reduced or if progress in correction has stalled. They should always be repeated prior to surgery.

When casting, extend the material distally over toes dorsally to inhibit extension through the metatarsal phalangeal joints as this can counteract the intended manipulation (Figure 6). The materials should be wrapped snugly with good contact at the midfoot and calcaneus to allow contouring for joint stabilization (Figure 7). When extending above the knee, the cast should extend to the groin crease and the knee should be in 80-90 degrees of flexion with no internal or external rotation through the knee joint (Figure 8). 

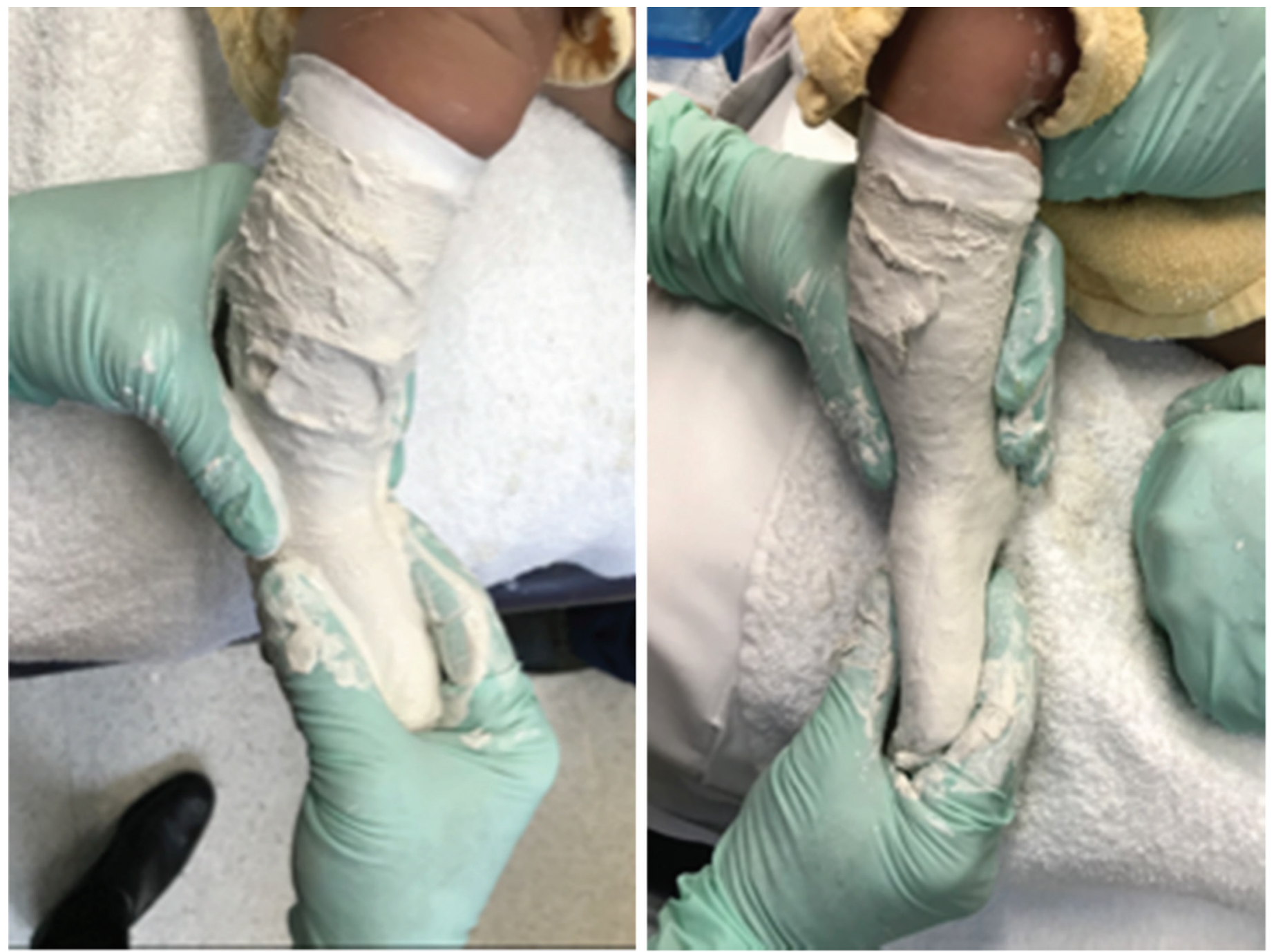

Figure 5. Clinical photographs demonstrating the manipulation for the final cast. With TNJ congruency, plantarflexion through the ankle is performed with continued adduction and supination. Mold the medial arch to maintain TNJ reduction with the right thumb on the dorsal navicular and the index under the talar head.

If surgery is not immediately following casting, a static custom ankle-foot-orthosis (AFO) is made to wear full time during the interim. Parents are taught stretches to perform daily. When a date for surgery is confirmed, two to three preoperative casts should be performed depending on the severity of their deformity.

\section{Minimally Invasive Technique}

If the TNJ reduces or partially reduces on radiographs at the conclusion of casting, minimally invasive surgery to complete the correction is scheduled and this author's preferred approach for primary surgery. The optimal age for surgery is debated. Due to the risks associated with general anesthesia, one should be cautious if operating before 9 months of age. Surgery is done with the patient supine on a radiolucent table under general anesthetic with a thigh tourniquet. A $3 \mathrm{~cm}$ medial incision is made over the distal tibialis posterior tendon ending at its insertion on the navicular. The tibialis posterior is isolated from its sheath and z-lengthened for plication after reduction. The TNJ is identified, using fluoroscopy if needed, and the capsule opened medially and dorsally. The lateral capsule can also be released if preoperative 

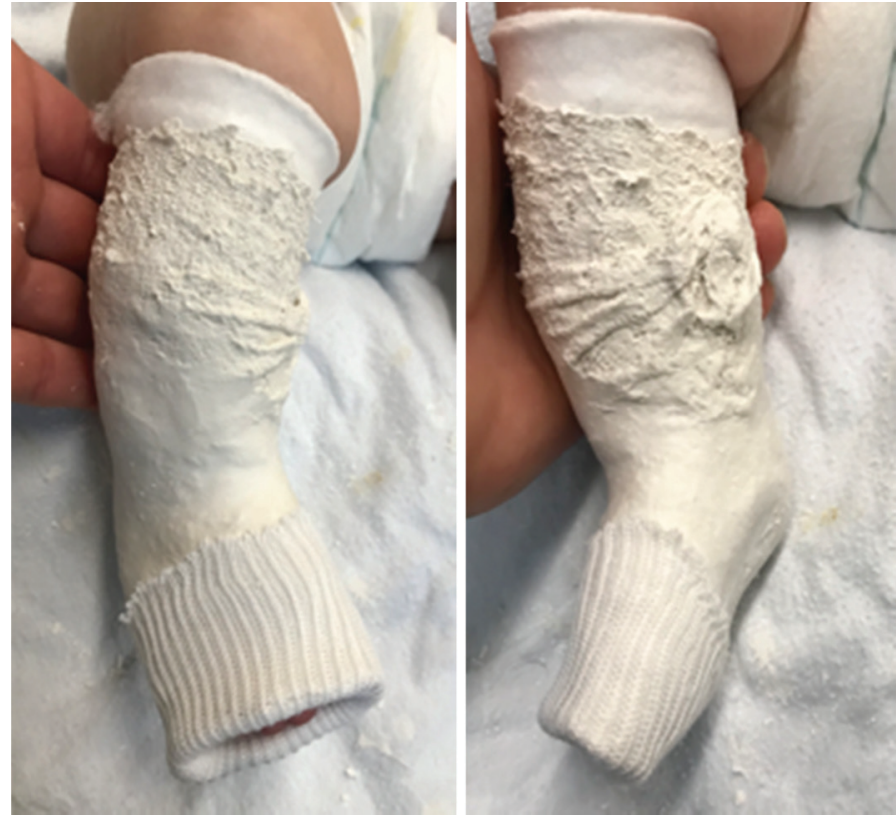

Figure 6. Clinical photographs demonstrating the lower leg cast portion with material extending distally over the toes.

reduction was not achieved. The plantar capsule is left intact. The percutaneous Achilles tenotomy is then performed with a Beaver blade, $1 \mathrm{~cm}$ above the tendon insertion on the calcaneus. The blade enters the skin from the medial side and then is positioned adjacent to the anterior surface of the tendon. The blade is turned 90 degrees posterior, and the tendon transected in an anterior to posterior direction to ensure the belly of the blade is never facing the posteromedial neurovascular bundle (Figure 9).

If the TNJ joint still does not reduce, the surgeon should identify and release any anomalous fibrous tissue that commonly is found between the TNJ capsule and the ankle joint capsule attaching to the distal tibia. The medial subtalar joint (STJ) capsule, below the talar neck and heading to the middle facet, might also need to be opened. This also enables a blunt curved instrument, such as a freer, to be placed under the talar neck to aid in reducing the TNJ (Figure 10).

Once reduction is achieved, a Steinman pin or K-wire, typically $1.6 \mathrm{~mm}$ diameter, is inserted retrograde in the center of the talar head through the talar body. It is important to be centered in the head to ensure concentric

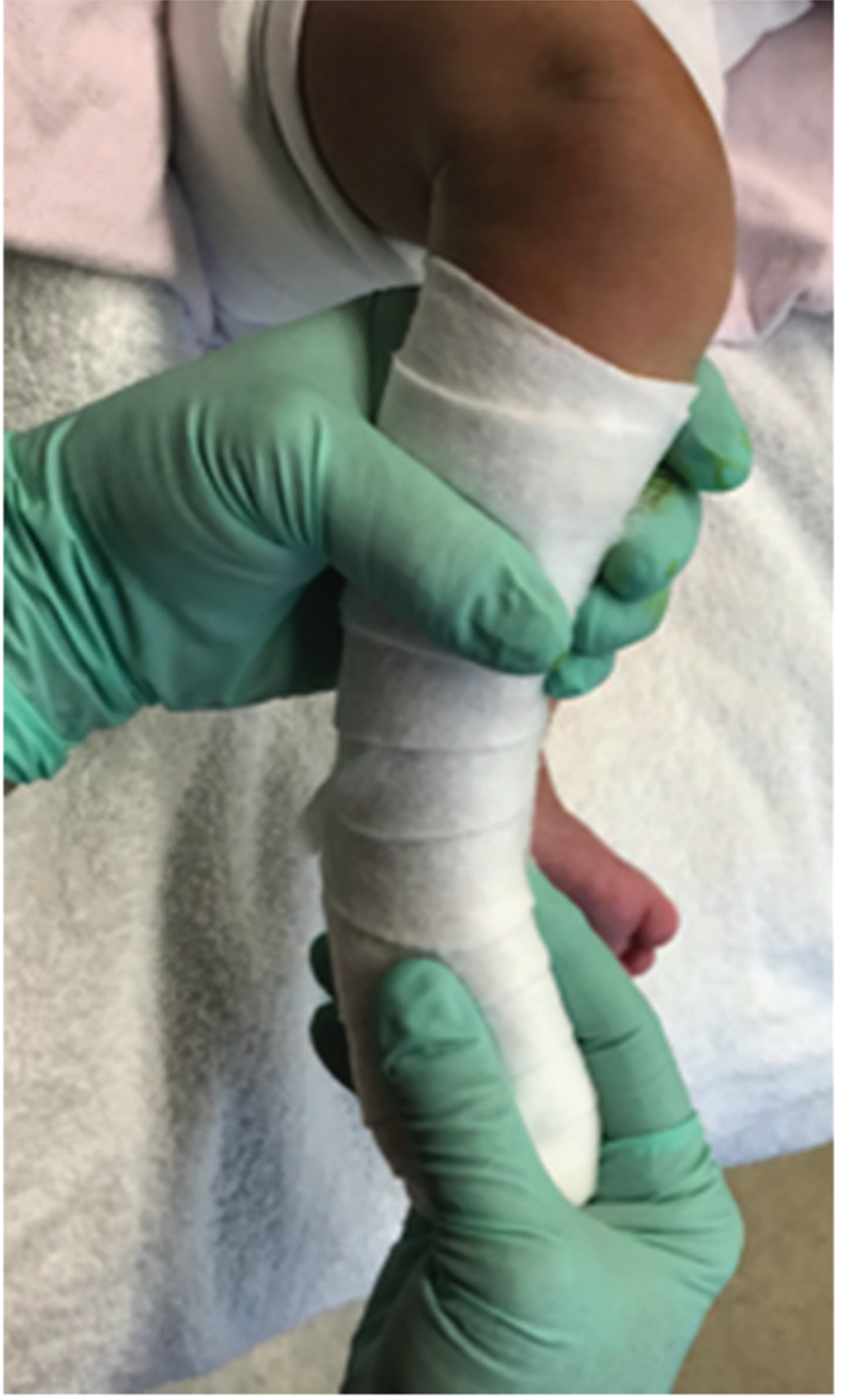

Figure 7. Clinical photograph demonstrating Webril padding with minimal layers and snug contact without wrinkles.

reduction of the TNJ. The pin should also be centered in the talar body on the AP and lateral radiographs.

Dorsiflex the ankle before driving the pin out the back of the talus to avoid the pin traversing into the distal tibia. Cut the sharp tip of the pin that has exited posteriorly. Once the pin tip is buried in the talar head, reduce the TNJ and run the wire antegrade until it exits out the dorsomedial forefoot. Ensure the wire is buried within the talar body posteriorly to avoid prominence within the ankle joint (Figure 11). Make a small incision where the pin has penetrated on the forefoot. Cut and bend the pin, 


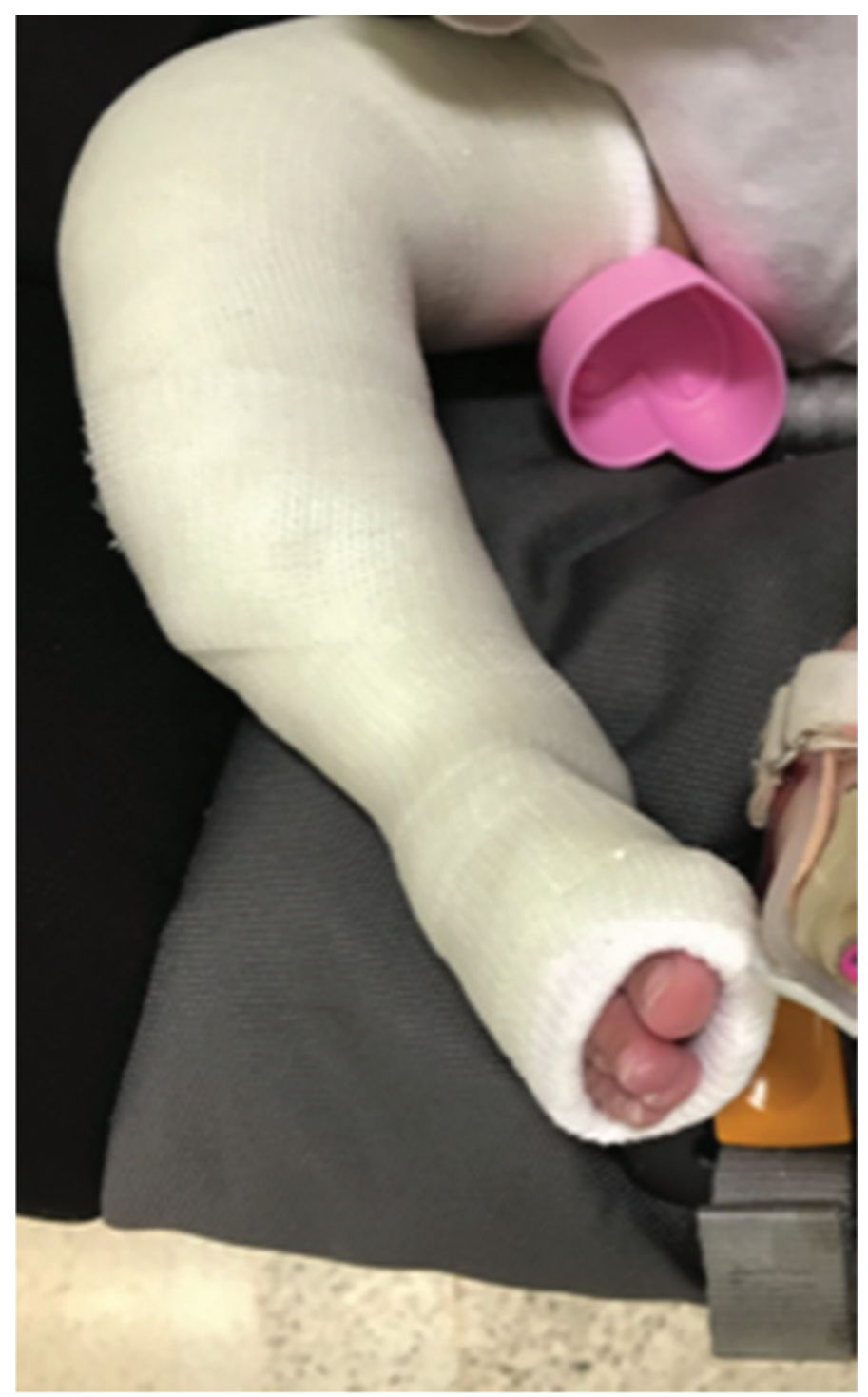

Figure 8. Clinical photograph demonstrating long leg cast extended to the groin crease at the thigh with a 90-degree bend at the knee.

then bury it within the incision. Although not described in Dobbs' technique, this author prefers to close the TNJ capsule tightly and repair the tibialis posterior tendon with side-to-side sutures, plicating both medial structures for added stability to the reconstruction. The incisions are closed, and an above knee cast applied with a mold of the arch and neutral ankle dorsiflexion. The postoperative protocol is delineated in Table 2. Pins are removed under sedation in a procedure room or general anesthesia in the operating room. The AFO is fit at the time of the pin removal.

\section{Troubleshooting the Irreducible CVT}

If the TNJ cannot reduce with the above technique additional releases are required. If plantarflexion of the ankle is less than 25 degrees, a fractional or z-lengthening of the extensor digitorum longus (EDL) should be performed through an anterior incision $1 \mathrm{~cm}$ above the ankle. Lengthening of the extensor hallucis longus (EHL) can be added through the same incision if the joint is still not reduced. In these cases, a second pin across the calcaneocuboid or TNJ should be considered.

If midfoot cannot be adducted $>10$ degrees, a fractional or z-lengthening of peroneus brevis is performed through a lateral incision. If deformity persists, release the lateral subtalar joint through sinus tarsi and lateral TNJ capsule. Peroneus longus can also be lengthened if needed but given its insertion plantar on the first metatarsal, this tendon helps maintain muscle balance postoperatively and should be lengthened prudently.

If the foot is very stiff or is a recurrence, and there was little improvement with casting, more extensive releases might need to be considered instead of the minimally invasive technique. When there is limited plantarflexion, a dorsal approach is useful as it allows exposure of the tight lateral and dorsal structures. Through a transverse incision, the peroneus brevis and tertius, toe extensors, tibialis anterior, lateral subtalar joint, calcaneocuboid joint and TNJ can all be accessed and released or lengthened if needed. One should start with the tendons, anomalous fibrous bands, and then joint capsules in an à la carte approach to achieve reduction (Figures 12-14).

If there is significant equinus or posterior capsule tightness without significant dorsolateral contracture, such as in patients with arthrogryposis, a posterior release is likely required. This author prefers to extend the medial approach to a Cincinnati incision, as opposed to the previously described medial and dorsal approaches, as this gives excellent exposure to the posterior release of ankle and subtalar joints 

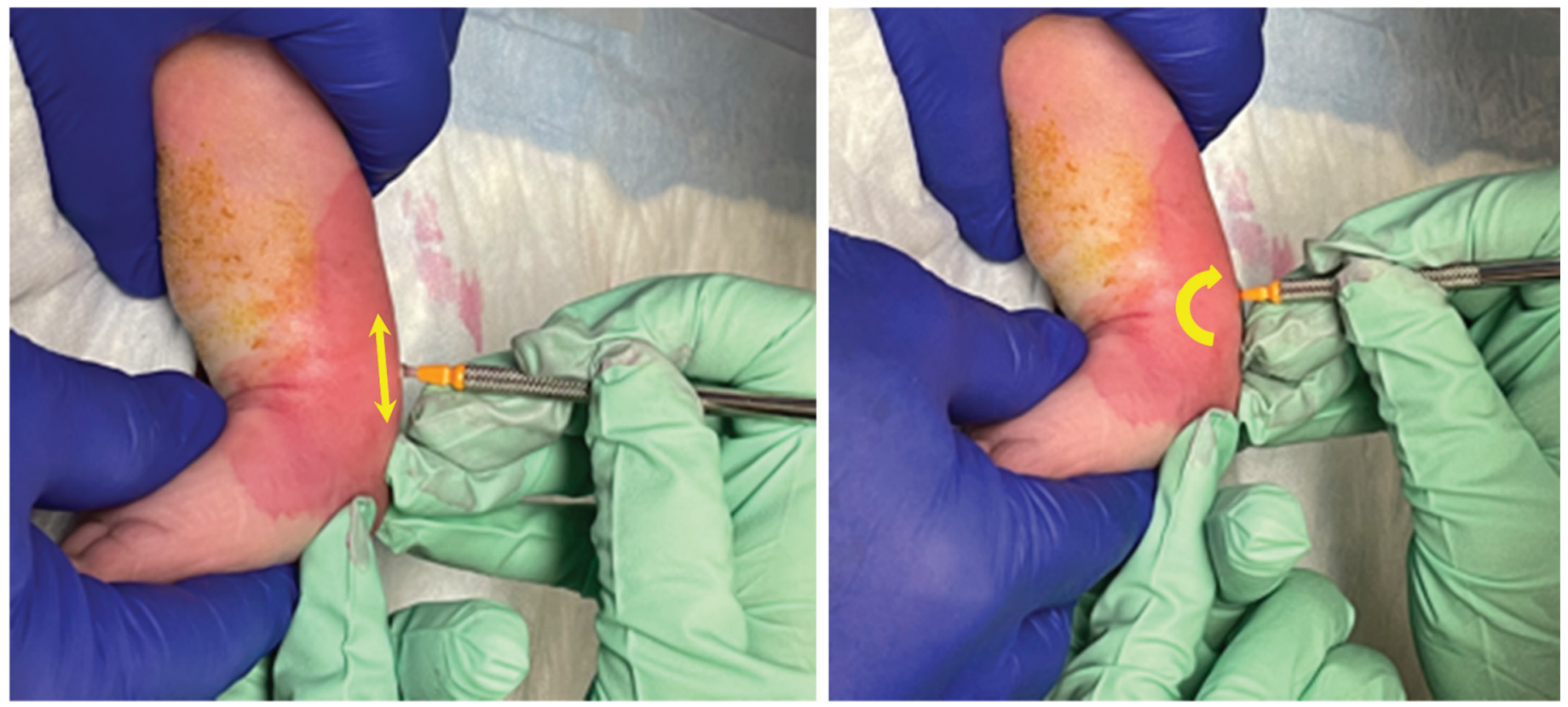

Figure 9. Clinical photographs demonstrating a percutaneous Achilles tenotomy. A Beaver blade is inserted 1cm above the calcaneal apophysis on the medial side of the tendon in line with the tendon (proximal-distal arrow). The blade is then turned 90 degrees posteriorly to sever the tendon (curved arrow).

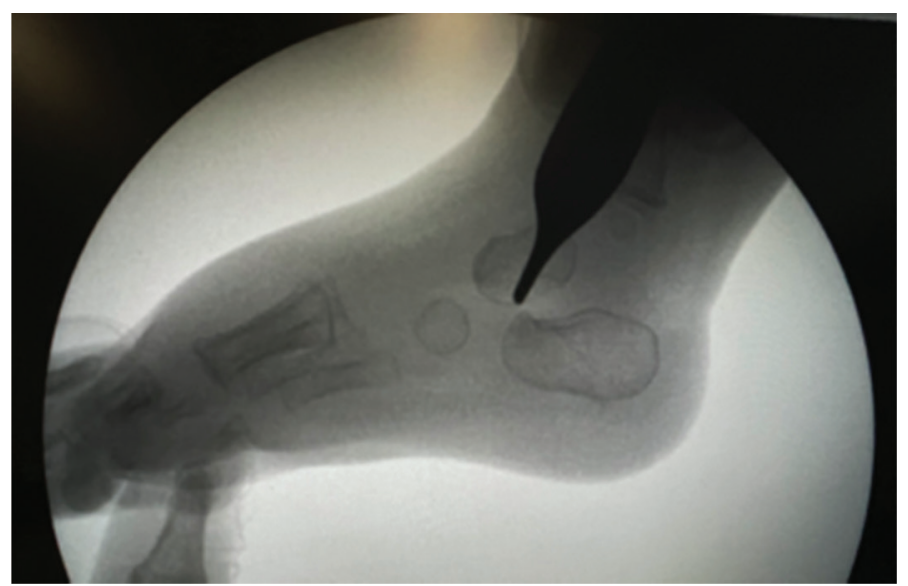

Figure 10. Intraoperative radiograph demonstrating a forcep under the talar neck. An air arthrogram is seen in the subtalar joint after its release.

(Figure 15). It also allows visualization of the tight posterolateral structures including the calcaneofibular ligament, and sheath of the peroneal tendons will likely also need to be released. In the case that dorsolateral and posteromedial structures require release, caution must be employed to avoid risk of osteonecrosis and/ or wound healing issues. This author will use a small lateral approach at the sinus tarsi in addition to a limited posteromedial Turco style incision, releasing only those structures that are required and maintaining thick, soft tissue flaps.

If the TNJ still cannot be reduced, consider naviculectomy. After age 2 to 3 years, the medial column overgrowth may be too significant for a reduction of the TNJ with a minimally invasive or soft tissue-only approach. Naviculectomy can be performed through a medial or dorsal approach ${ }^{25}$ (Figures 15 and 16). The tibialis posterior should be carefully detached from the navicular and advanced to the medial cuneiform and residual TNJ capsule plantarmedially. In young children, this can be done with sutures through the bone and to the periosteum. Older children may need the tendon secured with an interference screw or suture anchor.

The indications for talectomy and arthrodesis will not be discussed in this paper. Talectomy is typically avoided in ambulatory children and syndromic feet. ${ }^{23}$ This author reserves arthrodesis for older children with severe rigid 


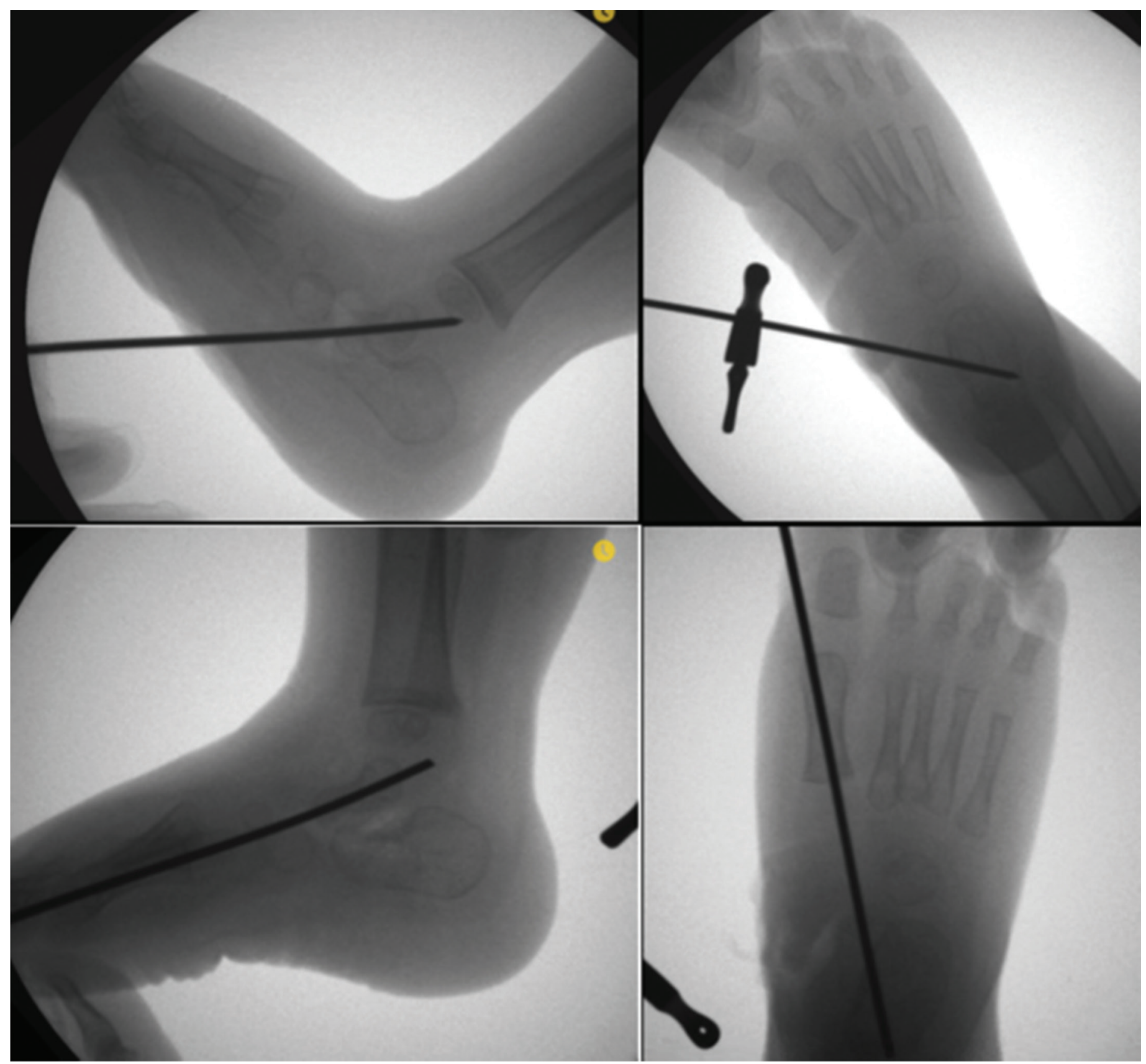

Figure 11. Intraoperative radiographs demonstrating retrograde pin placement across the talonavicular joint. The top two images show the lateral and AP radiographs confirming placement of pin centered in talar head and body. The bottom two images show final position once wire has been advanced antegrade across the reduced joint and exiting dorsomedially.

deformities not amenable to joint-sparing techniques described above.

For revision cases or patients requiring extensive releases, the postoperative protocol is adjusted only in that the pin(s) are kept in place for 12 weeks and the bracing period may be extended. AFOs are worn full time during skeletal growth for patients with arthrogryposis or progressive neuromuscular conditions.

\section{Comparison to Other Methods}

Unlike the clubfoot literature, there are no published guidelines for CVT management or general consensus 
Table 2. Postoperative and Bracing Protocol for Congenital Vertical Talus Management

\begin{tabular}{|c|c|c|}
\hline \multirow{8}{*}{$\begin{array}{l}\text { Postoperative } \\
\text { Protocol }\end{array}$} & \multirow{3}{*}{3 weeks } & $X$-ray in cast to ensure no pin migration \\
\hline & & $\begin{array}{l}\text { Above knee cast change to add } 10-15 \\
\text { degrees of ankle dorsiflexion }\end{array}$ \\
\hline & & Nonweight bearing \\
\hline & \multirow{3}{*}{6 weeks } & Mold AFO \\
\hline & & Change to short leg cast if age $>2$ years \\
\hline & & Continue to avoid weight bearing \\
\hline & \multirow{2}{*}{$\begin{array}{l}\text { 8-12 } \\
\text { weeks }\end{array}$} & $\begin{array}{l}\text { Go to operating room to remove pins, } \\
\text { x-ray, and fit AFO }\end{array}$ \\
\hline & & Next follow-up in 2 months \\
\hline \multirow{7}{*}{$\begin{array}{l}\text { Bracing } \\
\text { protocol }\end{array}$} & \multirow{3}{*}{$\begin{array}{l}\text { Brace } \\
\text { type }\end{array}$} & $\begin{array}{l}\text { Articulated AFO with free range and well } \\
\text { molded arch for daytime if walking }\end{array}$ \\
\hline & & $\begin{array}{l}\text { If }<2 \text { years old, use foot abduction brace } \\
\text { in neutral rotation with } 10 \text { degrees of } \\
\text { dorsiflexion at night }\end{array}$ \\
\hline & & $\begin{array}{l}\text { If } \geq 2 \text { years old, use AFO at night locked in } \\
\text { neutral }\end{array}$ \\
\hline & \multirow{4}{*}{$\begin{array}{l}\text { Brace } \\
\text { schedule }\end{array}$} & Full time for 2 months \\
\hline & & $\begin{array}{l}\text { Then wean } 3 \text { hours every } 2 \text { months until } \\
\text { nighttime only for minimum } 12 \text { hours ( 8 } \\
\text { months) }\end{array}$ \\
\hline & & $\begin{array}{l}\text { Brace wear for } 2 \text { years total if isolated } \\
\text { deformity }\end{array}$ \\
\hline & & $\begin{array}{l}\text { If nonisolated, consider use throughout } \\
\text { growth depending on diagnosis }\end{array}$ \\
\hline \multirow{3}{*}{$\begin{array}{l}\text { Follow-up } \\
\text { protocol }\end{array}$} & & Every 3 months till age 2 years \\
\hline & & Every 6 months till age 5 years \\
\hline & & Then annual to maturity \\
\hline
\end{tabular}

statements among surgeons. A recent review article by Wirth describes a similar approach to the casting and minimally invasive surgery presented in this article. ${ }^{34}$ Wirth also advocates for burying the pins but does not do a medial soft tissue plication. He, like Dobbs, does the tenotomy after the TNJ reduction. ${ }^{15,34}$ This author finds that in many cases, the tenotomy improves the ability to reduce the TNJ and therefore prefers to do the tenotomy before the reduction. Wirth removes the pin under anesthesia after 6 weeks and places the child in an AFO until the foot appears stable. ${ }^{34}$ Once the child is of walking age, they use a custom insole with an elevated medial arch. ${ }^{34}$ Wirth describes a similar approach as this author for the treatment of recurrent deformities, with initial casting followed by more extensive soft tissue releases and possible naviculectomy. ${ }^{34}$

Hafez and Davis published their series of 21 patients aged 1-17 months with a mean 6.5-year follow-up treated with the minimally invasive method. ${ }^{35}$ The five syndromic patients had lower functional scores and $29 \%$ recurrence, all occurring in the first postoperative year. None of the idiopathic feet had a recurrence, and no patients required adjunct procedures such as tibialis anterior tendon transfer or anterolateral soft tissue releases. The number of preoperative casts ranged from 2 to 12 . The wire was left outside the skin and a cast applied for 6 weeks. Foot abduction brace in neutral rotation and 10 degrees of dorsiflexion was applied for 23 hours a day for 2 months followed by nighttime wear only and AFO use in the day until the age of 2 years.

Dobbs did not describe medial plication of the capsule and/or tibialis posterior, however it was performed routinely in earlier techniques of extensive surgical release. ${ }^{15}$ In the original descriptions of the two-stage releases, the tibialis posterior tendon and medial TNJ capsules were plicated at the conclusion of the first stage with dorsal soft tissue releases. The second stage included the posterior releases. ${ }^{3,21,36}$ More recently, Saini et al. included a plication medially as part of their technique for CVT correction through a dorsal approach. $^{37}$

A technique this author does not typically perform is the transfer of the tibialis anterior tendon to the dorsal talar neck. Dobbs recommends it for children over 2 years of age (when plantarflexion is limited to less than 25 degrees after TNJ pinning and Achilles tenotomy with a fractional lengthening of the EDL). ${ }^{4}$ Other authors have reported performing of a full or split transfer of the tibialis anterior to the head or neck of the talus. El-Sobky et al. also describe attaching the tendon to the plantar medial TNJ capsule in combination with a naviculectomy. ${ }^{25}$ Although the efficacy of these transfers has not been studied, the split transfer may be a safer 

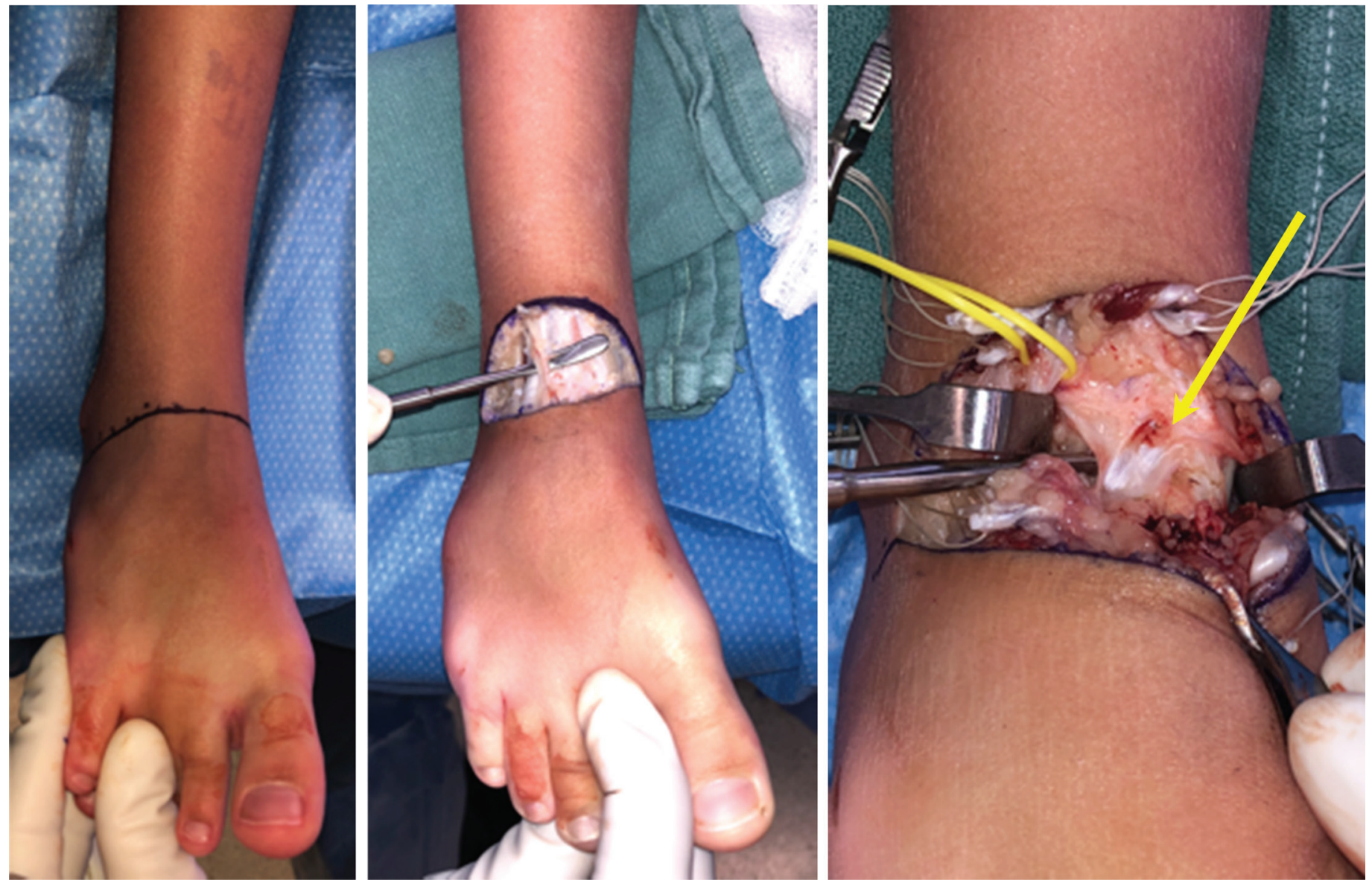

Figure 12. Intraoperative photographs of the dorsal approach for CVT. The left image shows the dorsal transverse incision from the sinus tarsi to the medial side of the TNJ. The middle image shows the superficial peroneal nerve in the superficial dissection-it is protected throughout the operation. The right image shows the anomalous soft tissue bands between the talus and distal tibia that need to be released (yellow arrow). The vessel loop is around the anterior neurovascular bundle.

option than a full transfer, as it does not alter muscle balance while providing internal support for the talus. Complete transfer of the tibialis anterior could lead to worsening muscle imbalance and possible development of a cavus foot deformity, as it leaves the peroneus longus unopposed. This risk would be greatest in neuromuscular patients.

There remains controversy as to the best surgical approach for extensive soft tissue release in CVT. Use of the Cincinnati incision alone (without a dorsal or lateral approach) has been related to risks of inadequate reduction of the TNJ and talar osteonecrosis. ${ }^{18,20}$ The dorsal approach has been described with a transverse incision $^{38,39}$ and a single straight midline incision ${ }^{16,21}$ with good results and fewer complications than posteromedial releases, however the tight posterior tissues are not surgically addressed. Sanzarello et al. reported on nine cases of neglected CVT treated with a single stage 2-incision soft tissue release using a posteromedial Turco-style incision and a lateral approach over sinus tarsi. ${ }^{40}$ They avoided dorsal extension of incisions, kept incisions as small as possible, and maintained thick, soft tissue flaps. Wire was kept for 5 weeks and AFO applied subsequently. At a mean 2.6 years follow-up, results including patient reported outcomes were good, and no osteonecrosis occurred. Malhotra and Shah reported on 19 children with idiopathic and nonidiopathic CVT with a mean age of 27.5 months treated with primary soft tissue releases with 

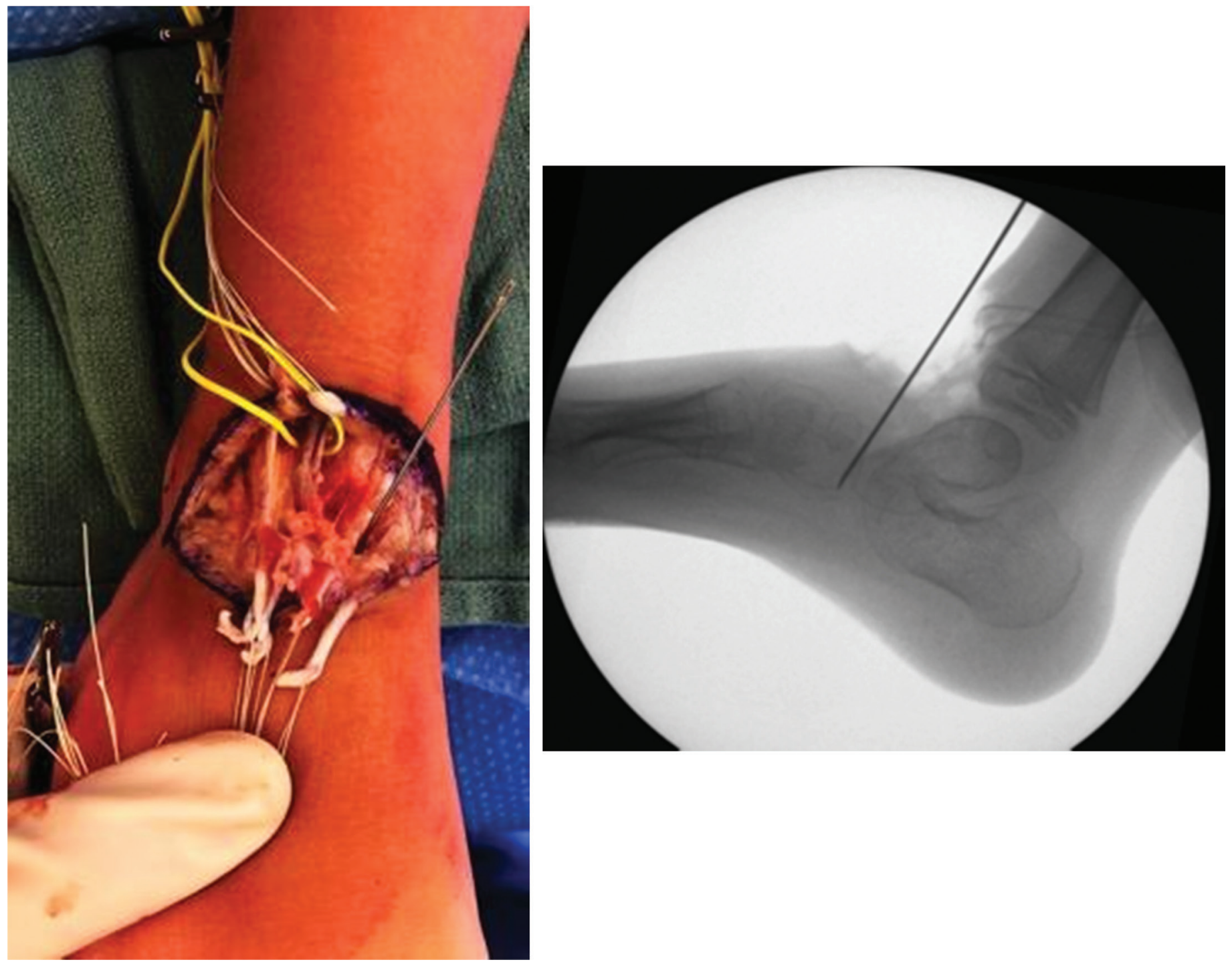

Figure 13. Intraoperative photograph and radiograph demonstrating the TNJ capsulotomy from a dorsal approach. The left image shows the tagged tendon ends of the EDL, EHL, and Tibialis Anterior that have been z-lengthened. The vessel loop is around the anterior neurovascular bundle. The Keith needle is entering the TNJ from dorsal. The lateral radiograph confirms the location of the needle in the TNJ.

a dorsal and posterior incision. ${ }^{38}$ Mean follow-up was 5.5 years. Their dorsal approach was similar to the author's described above but peroneals were not lengthened and the calcaneocuboid joint was routinely released. The posterior incision was vertical for an open Achilles lengthening and extended if the posterior capsules also needed releasing. The wire was kept for 6 weeks, then an AFO used for 6 months. Idiopathic feet had better postoperative range of motion, but all other outcomes studied were similar between the groups.
Naviculectomy has been recommended as both a primary and salvage procedure for congenital vertical talus. It is described in combination with a posterolateral release for deformity correction in older children. ${ }^{22,24}$ The upper age limit for this procedure is unknown. El-Sobky et al. have also described removing the navicular and the medial cuneiform in a 5-year-old child with arthrogryposis with good results at 2 years. ${ }^{25}$ Like this author, they avoid talectomy in ambulatory children. ${ }^{25}$ 

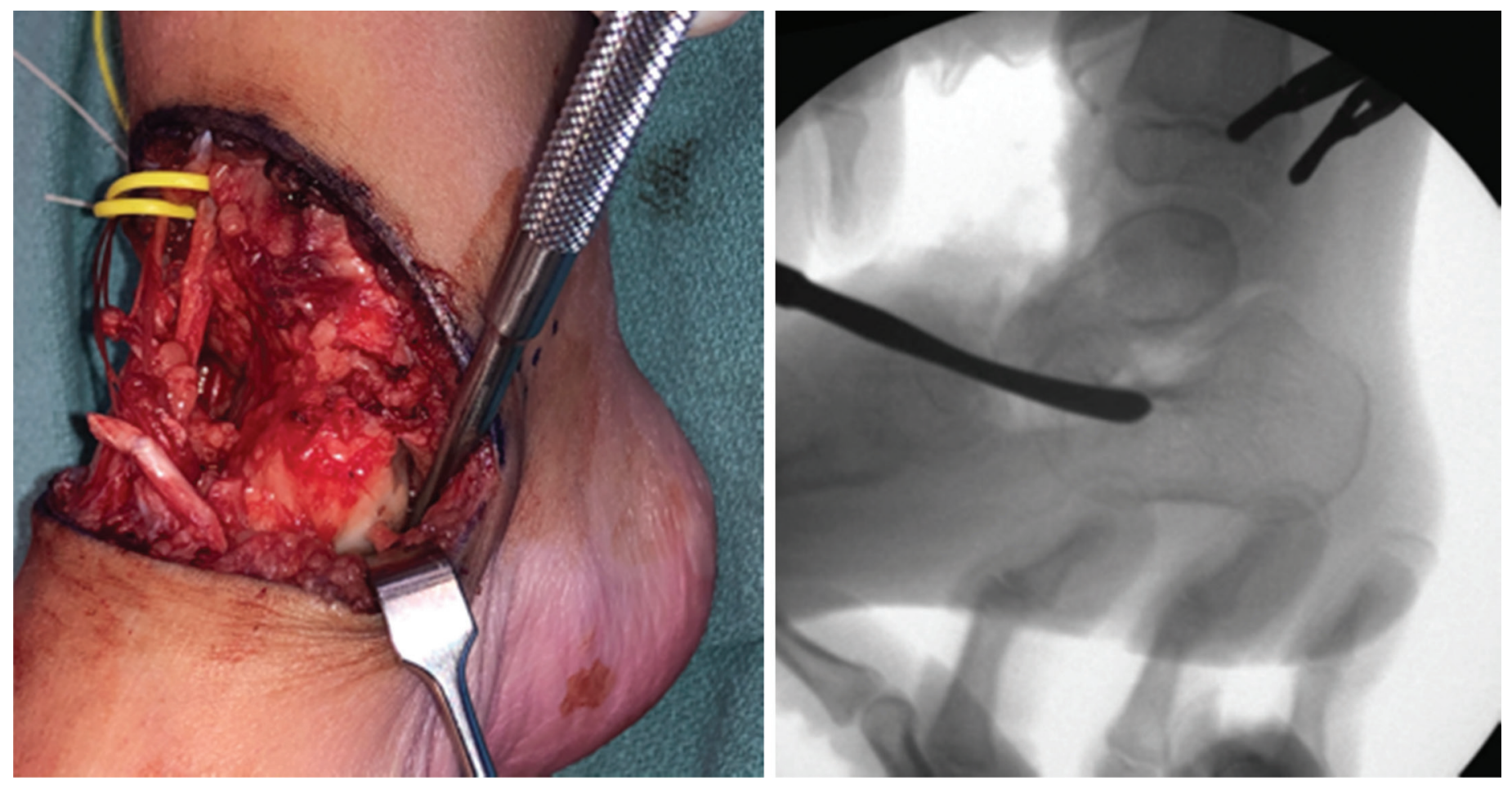

Figure 14. Intraoperative photograph and lateral radiograph demonstrating the reduction of the TNJ with a freer under the medial talar head from the medial aspect of the dorsal approach.
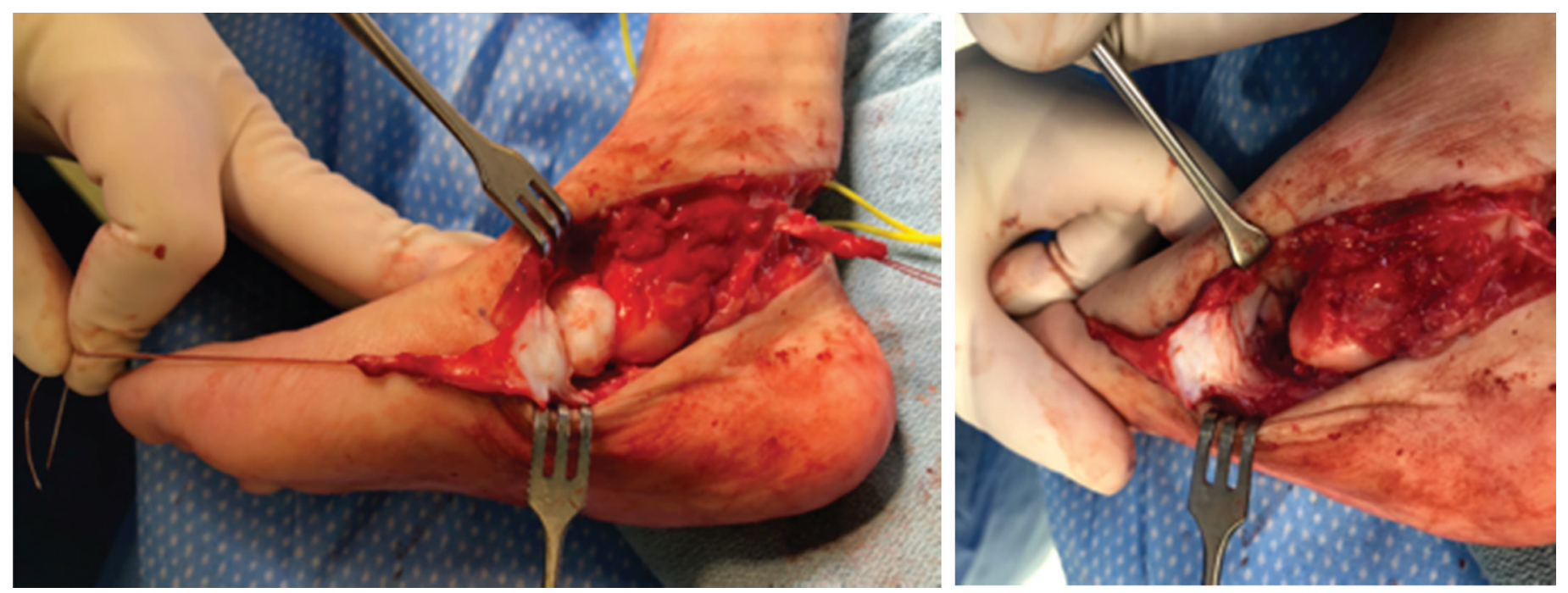

Figure 15. Intraoperative radiographs of a Cincinnati approach. The left image shows sutures in a z-lengthened tibialis posterior tendon, a vessel loop around the posteromedial neurovascular bundle, and the exposure navicular and TNJ. The right image shows the TNJ after excision of the navicular. Note the round contour of the cuneiforms that confirms nicely with the talar head.

\section{Summary}

This author's approach to correction of the congenital vertical talus offers a stepwise algorithm the surgeon can apply to a patient of any age with untreated, neglected, or recurrent deformity. Casting should always be attempted prior to surgery, and surgery should be performed with a deliberate à la carte approach to minimize complications. 


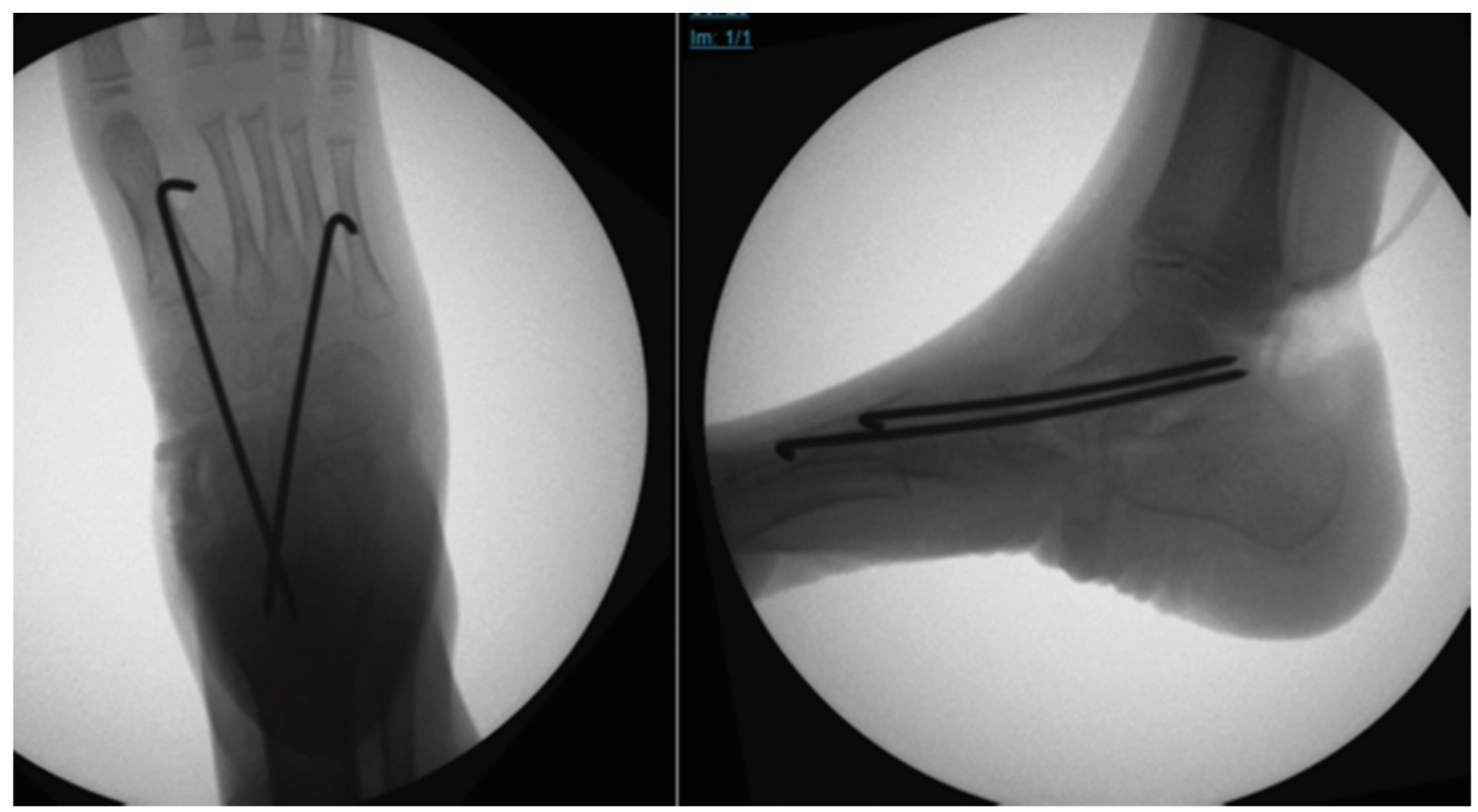

Figure 16. Intraoperative radiographs of the foot after naviculectomy with two K-wires stabilizing the TNJ.

\section{Acknowledgement}

Thank you to Barbara Harvey, PT, for her help in curating photos of the casting process and providing input to the written casting technique.

\section{Additional Links}

- Textbook-Mosca VS. Principles and Management of Pediatric Foot and Ankle Deformities and Malformations, Philadelphia, PA: Wolters Kluwer/ Lippincott Williams \& Wilkins, 2014

- POSNA 2015 Abstract — https://posna.org/AnnualMeeting/Past-Abstracts/Past-Abstract-Detail?itemid=754, Treatment of Congenital Vertical Talus: Comparison of Minimally Invasive Versus Traditional Surgical Technique With Minimum 5-Year Follow-Up, Matthew Dobbs, MD, Washington University School of Medicine, Saint Louis, MO

\section{References}

1. Lamy L, Weissman L. Congenital convex pes valgus. J Bone Joint Surg Am. 1939;21:79-91.
2. Herndon $\mathrm{CH}, \mathrm{Heyman} \mathrm{CH}$. Problems in the recognition and treatment of congenital pes valgus. J Bone Joint Surg Am. 1963;45:413-429.

3. Jacobsen ST, Crawford AH. Congenital vertical talus. J Pediatr Orthop. 1983;3:306-310.

4. Alaee F, Boehn S, Dobbs MB. A new approach to the treatment of congenital vertical talus. J Child Orthop. 2007;1:165-174.

5. Ogata K, Schoenecker PL, Sheridan J. Congenital vertical talus and its familial occurrence: an analysis of 36 patients. Clin Orthop Relat Res. 1979;139:128-132.

6. Townes PL, Dehart GK Jr, Hecht F, et al. Trisomy 13-15 in a male infant. J Pediatr. 1962;60:528-532.

7. Uchida IA, Lewis AJ, Bowman JM, et al. A case of double trisomy: trisomy No. 18 and triplo-X. J Pediatr. 1962;60:498-502.

8. Mark PR, Radlinski BC, Core N, et al. Narrowing the critical region for congenital vertical talus in patients with interstitial 18q deletions. Am J Med Genet A. 2013;161A(5):1117-1121.

9. Alvarado DM, McCall K, Hecht JT, et al. Deletions of 5' HOXC genes are associated with lower extremity malformations, including clubfoot and vertical talus. J Med Genet. 2016;53(4):250-255.

10. Dobbs MB, Schoenecker PL, Gordon JE. Autosomal dominant transmission of isolated congenital vertical talus. Iowa Orthop J. 2002;22:25-27.

11. Dobbs MB, Gurnett CA, Pierce B, et al. HOXD10 M319K mutation in family with isolated congenital vertical talus. J Orthop Res. 2006;24(3):448-453.

12. Drennan JC. Congenital vertical talus. Instr Course Lect. 1996;45:315-322.

13. Sharrard WJ, Grosfield I. The management of deformity and paralysis of the foot in myelomeningocele. J Bone Joint Surg Br. 1968;50:456-465. 
14. Hamanishi C. Congenital vertical talus: classification with 69 cases and new measurement system. J Pediatr Orthop. 1984;4:318-326.

15. Dobbs MB, Purcell DB, Nunley R, et al. Early results of a new method of treatment for idiopathic congenital vertical talus. J Bone Joint Surg Am. 2006;88:1192-1200.

16. Seimon LP. Surgical correction of congenital vertical talus under the age of 2 years. J Pediatr Orthop. 1987;7:405-411.

17. Mazzocca AD, Thomson JD, Deluca PA, et al. Comparison of the posterior approach versus the dorsal approach in the treatment of congenital vertical talus. J Pediatr Orthop. 2001;21:212-217.

18. Duncan RD, Fixsen JA. Congenital convex pes valgus. J Bone Joint Surg Br. 1999;81:250-254.

19. Kodros SA, Dias LS. Single-stage surgical correction of congenital vertical talus. J Pediatr Orthop. 1999;19:42-48.

20. Stricker SJ, Rosen E. Early one-stage reconstruction of congenital vertical talus. Foot Ankle Int. 1997;18:535-543.

21. Coleman SS, Stelling FH III, Jarrett J. Pathomechanics and treatment of congenital vertical talus. Clin Orthop Relat Res. 1970;70:62-72.

22. Colton CL. The surgical management of congenital vertical talus. J Bone Joint Surg Br. 1973;55:566-574.

23. Abraham E, Quan Soon CH, Murphy A et al. Talectomy by medial surgical approach for congenital vertical talus in arthrogryposis multiplex congenita. Orthopedics. 2020;43(6):e623-e626. doi: https://doi. org/10.3928/01477447-20200812-01.

24. Clark MW, Ambrosia RDD, Ferguson AB. Congenital vertical talus: treatment by open reduction and navicular excision. J Bone Joint Surg Am. 1977;59:816-824

25. El-Sobky TA, Samir S, Mahmoud S. Naviculectomy for two ambulatory children with intractable congenital vertical talus: redefining the indications of an old technique. J Pediatr Orthop B. 2020;29(4):387-391 doi: https://doi.org/10.1097/BPB.0000000000000663.

26. Coleman SS. Complex Foot Deformities in Children. Philadelphia, PA: Lea \& Febiger; 1983

27. Grice DS. Further experience with extra-articular arthrodesis of the subtalar joint. J Bone Joint Surg Am .1955;37-A:246-259; passim.

28. Napiontek M. Congenital vertical talus: a retrospective and critical review of 32 feet operated on by peritalar reduction. $J$ Pediatr Orthop B $1995 ; 4: 179-187$
29. Chalayon O, Adams A, Dobbs MB. Minimally invasive approach for the treatment of non-isolated congenital vertical talus. J Bone Joint Surg Am. 2012;94:e73(1-7).

30. Aslani H, Sadigi A, Tabrizi A, et al. Primary outcomes of the congenital vertical talus correction using the Dobbs method of serial casting and limited surgery. J Child Orthop. 2012;6:307-311.

31. Wright J, Coggings D, Maizen C, et al. Reverse Ponseti-type treatment for children with congenital vertical talus: comparison between idiopathic and teratological patients. Bone Joint J. 2014;96-B:274-278.

32. Yang JS, Dobbs MB. Treatment of congenital vertical talus: comparison of minimally invasive and extensive soft-tissue release procedures at minimum five-year follow-up. J Bone Joint Surg Am. 2015;97:1354-1365.

33. Cooper DM, Dietz FR. Treatment of idiopathic clubfoot. A thirty-year follow-up note. J Bone Joint Surg Am. 1995;77:1477-1489.

34. Wirth T. Congenital vertical talus. Foot Ankle Clin. 2021;26(4):903-913. doi: https://doi.org/10.1016/j.fcl.2021.08.002.

35. Hafez M, Davis N. Outcomes of a minimally invasive approach for congenital vertical talus with a comparison between the idiopathic and syndromic feet. J Pediatr Orthop. 2021;41(4):249-254. doi: https://doi.org/10.1097/BPO.0000000000001769.

36. Walker AP, Ghali NN, Silk FF. Congenital vertical talus. The results of staged operative reduction. J Bone Joint Surg Br. 1985;67:117-121.

37. Saini R, Gill SS, Dhillon MS, et al. Results of dorsal approach in surgical correction of congenital vertical talus: an Indian experience. J Pediatr Orthop B. 2009;18(2):63-68. doi: https://doi.org/10.1097/ BPB.0b013e328321ce71.

38. Malhotra M, Shah H. Comparison of outcome between idiopathic and non-idiopathic congenital vertical talus treated with soft tissue release. J Pediatr Orthop B. 2021;30(5):458-466. doi: https://doi.org/10.1097/ BPB.0000000000000815.

39. Mosca VS. Principles and Management of Pediatric Foot and Ankle Deformities and Malformations. Philadelphia, PA: Wolters Kluwer/ Lippincott Williams \& Wilkins; 2014.

40. Sanzarello I, Nanni M, Perna F, et al. One-stage release by double surgical approach for neglected congenital vertical talus: results in a series of walking children in Tanzania. J Pediatr Orthop B. 2019;28(6):586-590. doi: https://doi.org/10.1097/BPB.0000000000000657. PMID: 31356505. 